\title{
Research on Evaluating the Logistics Model of B2C Web store in China
}

\author{
Hongyan Niu \\ Beijing Jiaotong University \\ Beijing, China \\ E-mail: niuhongyan52121@163.com
}

\author{
Zhengyi Ge, Xiaohong Yang \\ Beijing Jiaotong University \\ Beijing, China \\ E-mail: zhyge@bjtu.edu.cn
}

\begin{abstract}
In order to evaluate the logistics model of B2C web store at present in our country, a dynamic data envelope analysis (DEA) model was developed. Using the model analyzed a Beijing B2C web store's logistic model. Combined with the actual situation in our country, evaluation result shows that B2C web store logistics model should be appropriate to reduce the logistics outsourcing and improve the proportion of self-support logistics, but self-support logistics rhythm should be appropriate.
\end{abstract}

Keywords-B2C web store; Logistics model; Data Envelopment Analysis

\section{INTRODUCTION}

B2C e-commerce is a lot of various trading activities between enterprises and consumers via electronic data information on the information network ${ }^{[1]}$. Logistics service level of B2C web store is good or bad that decides the prosperity or decline of the company. The logistics model is a crucial key in determining the logistics cost and service quality of B2C web store. Now many large B2C web stores begin self-built logistics system, and in some unimportant areas use a third party to conduct logistics activities, forming mixed logistics model ${ }^{[2]}$. How effective these logistics modes are? Is there possible to improve or optimize? These issues are faced by most web stores.

At present the evaluation research of logistics pattern mainly adopts analytic hierarchy process (AHP) analysis method ${ }^{[3]}$. This method exist shortcomings of weight subjectivity and static. Using dynamic DEA method in B2C web store logistics model evaluation can effectively overcome AHP shortcomings and enhance the objectivity. At last, a case was analyzed, proposed a reasonable suggestion which provided a theoretical basis for China's B2C web store logistics model selection and improvement.

\section{DEA EVALUATION MODEL ESTABLISHMENT}

\section{A. DEA EVALUATION THOUGHT}

Data envelopment analysis (DEA) is an effective assessment method of multi input and multi output of the multiple Decision Making Units (DMUs). The basic idea of DEA method is that there are some DMUs forming being evaluated group, then input ratio and output ratio was analyzed comprehensively, taking each DMU the weights of input-output index as variables, using the linear programming operate and determine an effective production. Finally according to each DMU is or isn't DEA efficient, point out its cause and propose improvement direction and degree of non-DEA and weak DEA efficient.

\section{B. DEA INPUT-OUTPUT INDEX SYSTEM}

Following the principles of integrity, operability, adaptability, simplicity, scientific and objectivity, the selected input index of B2C web store logistics mode is $x_{j}$ : logistics cost index, including the investment of logistics facilities and equipment and the proportion of logistics outsourcing. Output index is $y_{j}$ : logistics service index (on time delivery rate, accuracy, safety ratio and satisfaction) and operating efficiency index (quick ratio, asset-liability ratio, turnover ratio of fixed assets, profit ratio and market share).

\section{DEA EVALUATION MODEL ESTABLISHMENT}

Choose dual programming model $D^{2} R$ [4] of the classic model $C^{2} R$.

$$
(D)\left\{\begin{array}{c}
\mathrm{m} \text { in } \theta=V_{D} \\
s \cdot t \cdot \sum_{j=1}^{n} x_{j} \lambda_{j}+s^{-}=\theta x_{0} \\
\sum_{j=1}^{n} y_{j} \lambda_{j}-s^{+}=y_{0} \\
\lambda_{j} \geq 0, j=1,2, \cdots, n \\
s^{-} \geq 0, \quad s^{+} \geq 0
\end{array}\right.
$$

$x_{j}=\left(x_{1 j}, x_{2 j}, \ldots, x_{m j}\right)^{T}, j=1,2, \ldots ., n$, namely the input index of $\mathrm{j}$ decision ;

$$
y_{j}=\left(y_{1 j}, y_{2 j}, \ldots, y_{m j}\right)^{T}, j=1,2, \ldots, n
$$
, namely the output index of $\mathrm{j}$ decision;

$\theta$ : coordinate development index;

$n$ : decision making uint;

$\lambda_{j}$ : request variables;

$s^{-}, s^{+}$: slack variables and surplus variables. 
Hypothesis the optimal solution for the model is $\theta_{j 0}{ }^{*} 、 \lambda^{*} 、 s^{-*} 、 s^{+*}$, according to theorem we can judge whether the DEA is efficiency or not: if $\theta_{j 0}{ }^{*}=1$, then decision making unit $j_{0}$ is weak DEA efficiency; If $\theta_{j 0}{ }^{*}=1$, and $S^{+^{*}}=0, S^{-^{*}}=0$, then decision making unit $j_{0}$ is DEA efficiency; If $\theta_{j 0}{ }^{*}<1$, then decision making unit $j_{0}$ is nonDEA efficiency.

\section{DEA EVALUATION}

The evaluation method with the DEA in logistics mode chiefly involves two factors: return to scale and technical efficiency. Return to scale is to measure the performance of increased input and output, namely, if the input is increased, what will happen to the output? Return to scale invariant is reasonable, namely, input and output will be grow in the same speed. Increased "return to scale" refers to that the growth rate of output will be higher than the input. The decline of "Return to scale" refers to that the growth rate of output is lower than the rate of growth in the input. Technical efficiency can evaluate input and output more effective, to measure whether the input and the output achieve the best condition or not and whether there is redundant input or insufficient output. The higher it values, the more efficient it inputs. When it is weak DEA efficient or non-DEA efficient, it suggests that there exists some redundancy in input and some deficiency in output.

Using $D^{2} R$ model, we can judge whether the technical efficiency and return to scale effective at the same time.

(1) $\theta^{*}=1$, and $S^{+^{*}}=0, S^{-*}=0$.Then the DMU

$j_{0}$ is DEA efficient, the technical efficiency and return to scale are effective at the same time.

(2) $\theta^{*}=1$, and $S^{+^{*}}>0$ or $S^{-^{*}}>0$, then the DMU

$j_{0}$ is weak DEA efficient, the technical efficiency and return to scale are not effective at the same time.

(3) $\theta^{*}<1$, Then the DMU $j_{0}$ is non-DEA efficient, the technical efficiency and return to scale are not effective.

We usually use optimal value of $\lambda_{j}$ in the model $C^{2} R$ to determine the return to scale of decision making units (DMU) ${ }^{j_{0}}$.

(1) If there is $\lambda_{j}^{*}\left(j=1,2, \ldots\right.$ n) made $\sum \lambda_{j}^{*}=1$, then the $j_{0}$ DMU for return to scale is invariant.

(2) If there is $\lambda_{j}^{*}(j=1,2, \ldots \mathrm{n})$ made $\sum \lambda_{j}^{*}<1$, then the $j_{0}$ DMU for return to scale is increase.

(3) If there is $\lambda_{j}^{*}(j=1,2, \ldots \mathrm{n})$ made $\sum \lambda_{j}^{*}>1$, then the $j_{0}$ DMU for return to scale is decline.

\section{THE EXAMPLE ANALYSIS}

A Beijing web company was founded in November 1999. In 2001, the number of day view was more than 500000, which became a success in the $\mathrm{B} 2 \mathrm{C}$ web stores. The company's logistics adopted mixed mode, namely selfconducting logistics and outsourcing logistics.

According to the choice of DMU requirements and considering the availability data, the degree of satisfaction was utilized as a comprehensive index to analyze, as the data of on time delivery rate, accuracy, safety ratio of the company did not collect completely.

Decision making units used the company's 2006-2010 data, as was shown in table 1[5] (Please see the end of this paper).

In order to analyze the company outsourcing logistics and self-conducting logistics whether reasonable, they were analyzed partly.

\section{A. LOGISTICS OUTSOURCING RESULTS}

Excel was used to solve the solution of DEA model. For example, the calculation results of 2008 as shown in table 2. Other calculation results are similar, So didn't display every solution.

TABLE 2. The calculation results of logistics outsourcing in 2008

\begin{tabular}{ccccccc}
\hline$\lambda_{1}{ }^{*}$ & $\lambda_{2}{ }^{*}$ & $\lambda_{3}{ }^{*}$ & $\lambda_{4}{ }^{*}$ & $\lambda_{5}{ }^{*}$ & $\sum \lambda_{j}{ }^{*}$ & $\theta_{08}{ }^{*}$ \\
\hline 0 & 0 & 0 & 0.937 & 0.123 & 1.061 & 0.921 \\
\hline
\end{tabular}

From the above data we could know that the company's return to scale had decreased in 2008, but the extent was not very greatly, tending return to scale invariant. Technical efficiency didn't reach the best situation. It suggested that there was redundant input or insufficient output.

Used a line graph to analyze the company's trend from 2006 to 2010, the overall operation of company was seen clearly, as shown in figure 1 :

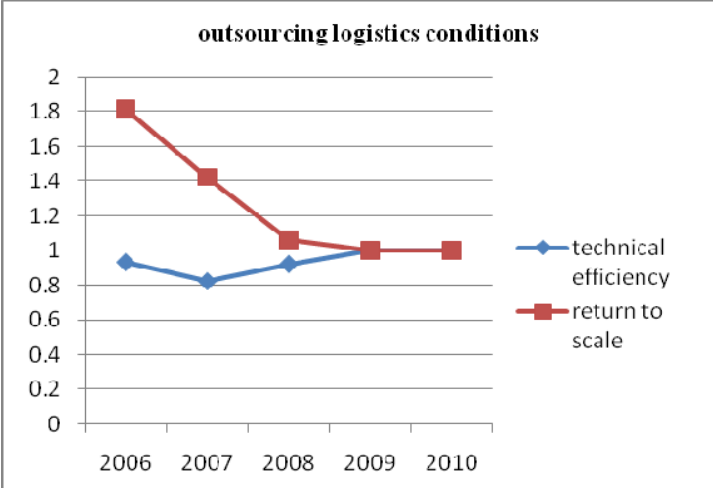

Fig.1 Return to scale and technical efficiency of logistics outsourcing from 2006 to 2010

The above chart showed that return to scale declined during 2006 to 2008 as $\sum \lambda_{j}^{*}>1$ and technical efficiency didn't achieve the best condition as $\theta^{*}<1$. In 2009 and 2010 return to scale was invariant and technical efficiency 
achieved the best condition. Explained that the B2C web store adopted smaller proportion of logistics outsourcing was a right choice, the smaller proportion of logistics outsourcing, the higher efficient of logistics. Self-built logistics center which aimed to raise the proportion of self-conducting logistics happened to have the same view with the B2C web store. But self-conducting logistics scale and speed to effective influence of logistics remains to be determined, the operating schedule made analysis.

\section{B. LOGISTICS OPERATING RESULTS}

The company logistics operating condition in 20062010 was shown in figure 2.

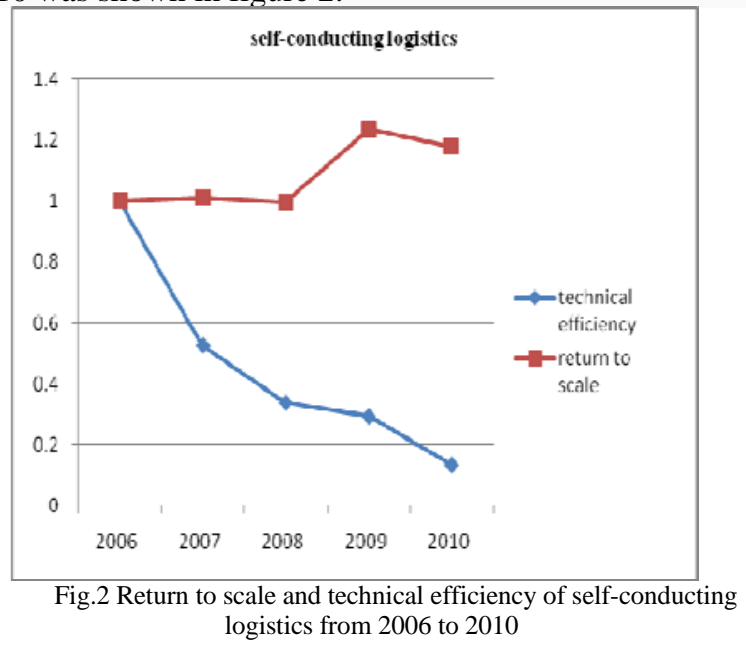

From the chart we can know that the company technical efficiency had been declining, this explained a phenomenon of too much input or too little output, input resource had not been fully used. The return to scale of the company was not change in 2006, in 2008 return to scale increased, in 2009 and 2010 return to scale was declined, indicating that these two years the increase of the output speed was less than the increase of the input, self-conducting logistics investment increased too fast. It should be appropriate to reduce self- conducting logistics input speed, in order to achieve the best efficiency of input and output.

\section{CONCLUSION}

(1) In view of the third party logistics enterprise developed slowly, it could not guarantee that B2C web store provide customers with high quality services, which restrict the development of the company, large B2C web store should be appropriate to reduce the logistics outsourcing.

(2) The B2C web store should base on the company's actual situation and analysis results to control the rhythm of self-conducting logistics system. A company should not invest blindly, emerging a phenomenon of high input and low output, making resources little used.

(3) With the level of third party logistics promoting, information technology upgrading, the proportional of selfsupport and outsourcing part should make dynamic adjustment. Promote the effective docking between selfconducing and outsourcing part through the information system of communication platform, to realize seamless connection, with a flexible method to deal with the internal and external environment changes, to achieve the purpose of promoting the company development.

\section{REFERENCES}

[1] Zhang Yi. E-commerce and logistics[M]. Beijing: Tsinghua university press, 2000.

[2] Chen Hairong. The selection of logistics distribution model in B2C electronic business enterprise[J]. Small and medium-sized enterprise management and science and technology. 2009(4):223-224.

[3] Zhang Fang. The selection of logistics model for ecommerce in China [D]. Liaoning: Northeast Finance and Economic University, 2004.

[4] Ma Zhan-xing. Data envelopment analysis (DEA) model and method [M]. Beijing: Science Press, 2010.

[5] I research co. LTD. Chinese network shopping Jane version's report. http://www.iresearch.com.cn (2008). Accessed 25 December 2008

TABLE1. Logistics Input and Output of a Beijing Company from 2006 to 2010

\begin{tabular}{|c|c|c|c|c|c|c|c|c|}
\hline \multirow{6}{*}{ 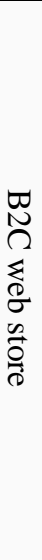 } & \multirow{6}{*}{ 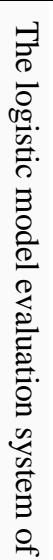 } & one class index & second class index & 2006 & 2007 & 2008 & 2009 & 2010 \\
\hline & & \multirow{2}{*}{$\begin{array}{l}\text { The logistics cost (input) } \\
\text { index }\end{array}$} & $\begin{array}{l}\text { Logistics facilities equipment } \\
\text { investment (million) }\end{array}$ & 6.45 & 12.38 & 16.97 & 27.06 & 55.93 \\
\hline & & & Logistics outsourcing proportion & 0.51 & 0.47 & 0.33 & 0.29 & 0.26 \\
\hline & & $\begin{array}{l}\text { Logistics service quality } \\
\text { (output) index }\end{array}$ & satisfaction & 0.682 & 0.668 & 0.675 & 0.696 & 0.723 \\
\hline & & \multirow{2}{*}{$\begin{array}{l}\text { Business efficiency } \\
\text { (output) index }\end{array}$} & Quick ratio & 0.580 & 0.450 & 0.330 & 0.310 & 0.320 \\
\hline & & & Asset-liability ratio & 0.947 & 0.954 & 0.943 & 0.941 & 0.495 \\
\hline
\end{tabular}




\begin{tabular}{|c|c|c|c|c|c|c|c|}
\hline \multirow{2}{*}{} & Fixed assets turnover & 0.857 & 0.821 & 0.793 & 0.769 & 0.742 \\
\cline { 3 - 7 } & profit ratio of sales & 0.178 & 0.180 & 0.164 & 0.220 & 0.210 \\
\cline { 2 - 7 } & Market share & 0.158 & 0.146 & 0.114 & 0.123 & 0.092 \\
\hline
\end{tabular}

(Note: the above data from annual report of the company website, airy consulting report, network shopping market research report, and personal collection.) 